\title{
Efecto de los Senósidos A y B sobre el Peristaltismo Intestinal Durante el Puerperio
}

\author{
Dres. Velasco-Chiriboga, A. ${ }^{*}$; Ferdomo, M. A. **
}

\section{Introducción}

La atonía intestinal es una complicación frecuente después de un parto eutócico y es especialmente alarmante durante el post-operatorio de la paciente que se somete a operación cesárea. En este último caso, en su estado más avanzado el íleo paralítico con distensión abdominal exagerada puede comprometer la cicatrización de las suturas abdominales y favorecer el desarrollo de adherencias e infección peritoneal. Por otra parte, su presencia dificulta el diagnóstico diferencial con otro tipo de patología que también se presenta con distensión abdominal: peritonitis, obstrucción intestinal.

Los factores etiológicos que contribuyen al estreñimiento postparto son múltiples, están implicados factores preparto cuando se trata de un estreñimiento crónico favorecido por la ingestión de alimentos de bajo residuo, costumbre frecuente en este período del embarazo. Los factores intraparto incluyen la disminución de volumen por hábitos alimenticios o por la aplicación de un enema evacuante durante el parto, deshidratación como resultado de la

* Prof. Asociado de Obstetricia y Ginecología - Facultad de Medicina, Universidad Nacional.

* Ginecobstetra del Departamento de Obstetricia y Ginecología - Facultad de Medicina, Universidad Nacional. poca ingestión de líquidos durante el parto o hemorragia durante el alumbramiento, la limitación exagerada de alimentos durante el parto y la aplicación de narcóticos o analgésicos durante el primer período del trabajo de parto. Los factores postparto incluyen el dolor de la episiotomía retención voluntaria de la defecación por temor al dolor, presencia de hemorroides o prolapso de la mucosa rectal, fisuras o laceraciones. Algunos investigadores consideran que la sobrecarga hormonal, especialmente progesterona, pueda ser un factor dominante.

En una encuesta previa efectuada en nuestra institución, el $65 \%$ de las pacientes puérperas presentaron estreñimiento dentro de los primeros cinco dias postparto.

Favorecer el peristaltismo y tránsito intestinal beneficia a la paciente puérpera especialmente cuando se ha sometido a operación cesárea. Muchas drogas se utilizan para lograr este fin, algunos laxantes irritantes como la Fenolftaleína provocan defecación acuosa que frecuentemente se acompaña de cólicos. También se utilizan los laxantes de bulto como las sales de magnesla, que retienen y absorben líquido al intestino, producen una defecación rápida, acuosa, molesta, dolorosa; además, pueden alterar el equilibrio de los líquidos y electrolitos. Se utilizan también los coloides hidrofílicos: agar agar, psillium, que absorben agua y aumentan el bulto produciendo un estímulo 
mecánico que aumenta el peristaltismo. Los emolientes, petrolatos y aceites facilitan el movimiento por lubricación, produciendo un escurrimiento constante por el ano, con las molestias subsecuentes

Otras drogas estimulan el mecanismo neuromuscular peristáltico produciendo una imitación perfecta del proceso fisiológico de la defecación normal.

Los senósidos A, B y $C$ * extraídos del pericarpio de la casia acutifolia (Sen de Alejandría), son glucósidos activos, complejos de azúcares con el derivado antraquinónico rhein, han permitido la normalización farmacológica de los extractos del sen, planta que desde la antigüedad se utiliza como laxante eficaz y está desprovista de efectos colaterales.

Este trabajo se diseñó con objeto de evaluar la eficacia de los senósidos en el puerperio fisiológico y en post-operatorio de las cesáreas.

\section{Material y métodos}

En ell Servicio de Obstetricia del Instituto Materno-Infantil de Bogotá, se estudió una muestra de 4.0 pacientes con diagnóstico de estreñimiento funcional durante el puerperio o aritecedente de estreñimiento crónico.

La muestra se dividió en dos grupos:

Grupo A: lo integraron 20 pacientes con el antecedente de parto eutócico; estas pacientes no recibieron ningún tipo de anestesia ni medicación con acción neurovegetativa. Durante el puerperio recibieron la droga en estudio y algún analgésico tipo ácido acetilsalicílico o Piramidón.

Grupo B: lo formaron 20 pacientes que se sometiercn a operación cesárea, con anestesia peridural, sin ningún

* Senokot otro tipo de drogas de acción neurovegetativa.

Se excluyeron del estudio pacientes con diagnóstico de abdomen agudo, peritonitis o cualquier otra afección abdominal grave.

Ninguna paciente recibió enema evacuante.

A las pacientes se les administraron dos tabletas de senósidos de $8.6 \mathrm{mg}$ diarios durante 2 días; en caso de operación cesárea el tratamiento duró 3 ó 4 días. El tratamiento se suspendió cuando la paciente presentó su primera evacuación intestinal.

Para evaluar los resultados se utilizó el siguiente criterio: Se calificó el tra. tamiento como excelente cuando la paciente evacuó entre 6 y 10 horas des. pués de la administración del fármaco. Bueno, cuando la paciente evacuó entre las 10 y 20 horas subsiguientes y malo en aquellos casos en que la paciente no evacuó después de 20 horas.

\section{RESULTADOS}

\section{Grupo A:}

Lo integraron 20 pacientes, 7 con el antecedente de estreñimiento crónico durante el embarazo y 13 con estreñimiento funcional durante el puerperio.

De las pacientes con antecedente de esteñimiento crónico, con la admi. nistración de senósidos $A$ y $B$ se obtuvieron resultados excelentes en 2 $(28.57 \%)$, buenos en $4(54.14 \%)$ y malos en $2(28.5 \%)$.

En aquellos con estreñimiento funcional, los resultados fueron excelentes en 7 pacientes $(53.84 \%)$, buenos en 1 $(7.96 \%)$ y malos en $4(38.46 \%)$.

En total, en este grupo $A$, el resultado fue el siguiente: 
Excelente en 9 pacientes $(45 \%)$, bueno en $5(25 \%)$, malo en $6(30 \%)$.

En términos generales, resultados favorables: $70 \%$ de los casos.

\section{Grupo B:}

En este grupo se incluyeron aquellas pacientes que se sometieron a operación cesárea segmentaria transperitoneal. Los resultados del uso de los senósidos $A$ y $B$ fueron los siguientes:

Excelente en 10 casos $(50 \%)$, bueno en $8(40 \%)$, malo en $2(10 \%)$.

Una paciente requirió tratamiento más de 4 días.

\section{Efectos colaterales}

No se apreció ningún efecto colateral en los grupos tratados, por tanto se considera que en las dosis utilizadas están libres de efectos colaterales.

\section{Comentarios}

En el presente estudio se demostró la eficacia de los senósidos A y $B$ en el $70 \%$ de pacientes en puerperio fisiológico y en el $90 \%$ de pacientes que se sometieron a operación cesárea.

Los resultados fueron similares a los que obtuvo Goya (4), quien publicó un $73 \%$ de eficacia en pacientes en puerperio fisiológico, 18 horas después de administrar la primera dosis.

Nuestros resultados son mejores que los obtenidos por Bauer (1), quien administró una dosis inicial de 2 comprimidos en un grupo de 6 pacientes; en las primeras 24 horas la droga fue eficaz sólo en 2 de ellas.

González (3) describió un 96\% de excelentes resultados, pero es necesario considerar que la primera evacua- ción se etectuó 48 horas después de iniciar el tratamiento. En nuestra observación se consideraron como malos los casos que sobrepasaron las 20 horas.

Los trabajos de Cuevas (2) no son comparables a los nuestros pues inicia el tratamiento solamente cuando la paciente lleva un período de constipación mayor de 57 horas.

El $92 \%$ de eficacia relatada por Scott (5) se basa en un período de observación muy largo, hasta 3 días después de administrar la primera dosis. Los resultados obtenidos dentro de las primeras 24 horas son muy pobres ( 25 casos en 540 pacientes puérperas).

Nuestras pacientes demostraron ser sensibles a la droga, en comparación con los resultados de otros investigadores.

\section{Resumen}

Se estudiaron 2 grupos de pacientes sometidas a tratamiento con senósidos A y B para combatir el estreñimiento crónico y el estreñimiento funcional del puerperio.

Un grupo de pacientes que tuvieron parto espontáneo y no recibieron ningún tipo de anestesia, se trataron con 2 tabletas de Senokot el primer dia, repitiendo el tratamiento al día siguiente. El $70 \%$ de pacientes evacuaron dentro de las primeras 20 horas del tratamiento.

En otro grupo de 2.0 pacientes, que se sometieron a operación cesárea, el tratamiento fue eficaz en el $90 \%$.

Se consideró el tratamiento como eficaz, fácil de administrar y carente de efectos colaterales; por tanto de gran utilidad en la práctica obstétrica. 


\section{Effect of A and B Senosides on intestinal peristalsis during puerperium}

\section{Summary}

Two groups of patients treated with $A$ and $B$ Senosides in order to fight both recurrent and functional constipation of the puerperium were studied.

A group of patients who has spontaneuos abortion and were not given any type of anesthesia, were treated with two Senokot tablets the first day, repeating the same treatment the following day. $70 \%$ of the patients evacuated during the first twenty hours of the treatment.

In the other group of patients, who were submitted to caesarean operation, the treatment was successful in $90 \%$ of the cases.

The treatment was considered to be efficient, easy to apply and with no side effects; therefore, it is very useful in obstetrics practise.

\section{Bibliografia}

1. BAUER, $H .:$ The treatment of atonic constipation, in puerperal and postoperative patients, with a senna preparation. Therapie del gegenwart, 100: 528, october 1961.

2. CUEVAS, M. L., RAMIPEZ, V. E.: Tratamiento de la constipación en pacientes obstétricas y ginecológicas. Semana médica de México. Vol. VLIII, N:742, septiembre 1968.

3. GONZALEZ, G., M.: Evaluación clínica del polvo de Sen como tratamiento de la cons. tipación intestinal en pacientes gineco-obstétricas. Biblio. méd. internacional. Nov., $\mathrm{N}^{\text {? }}$ 329, 1968.

4. GOYA, O., A.: PEREZ, V., A.: Valoración clínica de un producto a base de senosidos normalizados, en puérperas campesinas. México. Médico XVIII, Epoca. Vol. 3. N? $16,1958$.

5. SCOTT, R., S.: Management of constipation in obstetrics. A Clinical Report of 592 cases. Western medicine. Vol. 6, N $: 12$, dec. 1965. 